\title{
Synthesis and characterization of pH switching electrical conducting biopolymer hybrids for sensor applications
}

\author{
Ashutosh Tiwari \\ Received: 11 October 2007 / Accepted: 14 January 2008/Published online: 13 February 2008 \\ (C) Springer Science + Business Media B.V. 2008
}

\begin{abstract}
A novel electrically active, water soluble gum acacia-polyaniline (GA-PANI) hybrid was synthesized using ceric ammonium nitrate as initiator in acidic medium. The representative hybrid material was characterized using UV-visible, FTIR and SEM taking polyaniline as reference. The composition of aniline to gum acacia was tailored to optimize possible cross-linking in side the hybrid. The hybrid material exhibited $\mathrm{pH}$ switching electrical conductivity, which was decreased with increasing $\mathrm{pH}$ of the material. $I-V$ characteristics and acid-base sensitivity of the hybrid material were extensively investigated in order to find out its electronic behavior during current flow.
\end{abstract}

Keywords Gum acacia-polyaniline hybrid .

Electrical conductivity · Acid-base sensitivity

\section{Introduction}

Gum acacia (GA) is a complex arabinogalactan polysaccharide (Scheme 1), which exudates from the widely distributed acacia plants [1]. It is composed of D-galactose (40\%), L-arabinose (24\%), L-rhamnose (13\%), D-glucuronic acid $(21 \%)$ and $4-O$-methyl-D-glucuronic acid (2\%). GA possess a linear backbone of $\beta(1 \rightarrow 3)$ linked D-galactopyranosyl units to which D-galactopyranosyl, L-arabinofuranose and L-rhamnopyranose are attached as the side chains through $\alpha(1 \rightarrow 6), \alpha(1 \rightarrow 3)$ and $\alpha(1 \rightarrow 4)$ linkages, respectively [2]. The $\beta$-D-glucuropyranose and 4-O-methyl$\beta$-D-glucuronopyranose units are found as terminating

\section{A. Tiwari $(\bowtie)$}

Division of Engineering Materials, National Physical Laboratory,

Dr. K. S. Krishnan Marg,

New Delhi 110 012, India

e-mail: ashunpl@gmail.com groups. These uronic acid components are responsible for the polyanionic character of the biopolymer [3].

Gum acacia is an important substance in medicine and bacteriology. It has been reported that inorganic salt complex of gum acacia exhibits an electrical conduction like superionic conductor [4]. The chemical modification of the carbohydrate polymers with conducting polymers could be promising to prepare multifunctional conducting materials through oxidative-radical polymerization. The resulting materials will also be interesting in terms of compatibility with environment and biological systems.

In general, incorporation of conducting polymers such as polyaniline (PANI) into flexible biopolymer matrix could be resulted good process ability with the electrical conduction having the requisite properties like chemical stability toward dopants and solubility under readily accessible conditions. Gum acacia has gained growing interest to prepare ion conducting biopolymeric gel complexes [5]. Moreover, materials showed electrical conductivity and may have good compatibility for the hybrid formation with PANI.

Polyaniline (PANI) is proven as a promising conducting organic polymer because of its wide technological applications. It is continuously reformed day by day through the modulation of doping or by introducing functionality for making it more attractive for technological applications [6-7]. Recently few works have been reported on the chemical modification of carbohydrate polymer with PANI such as a semi-interpenetrating based chitosan/polyaniline and chitosan-polyaniline copolymers studied under different $\mathrm{pH}$ conditions [8-11]. The produced materials have found specific applications in the area of biosensors [12-13]. However, no more attention has been devoted on the chemical modification of anionic carbohydrate polymers with polyaniline.

To realize more sensitive and selective new functional materials of polyaniline for sensors development, the 


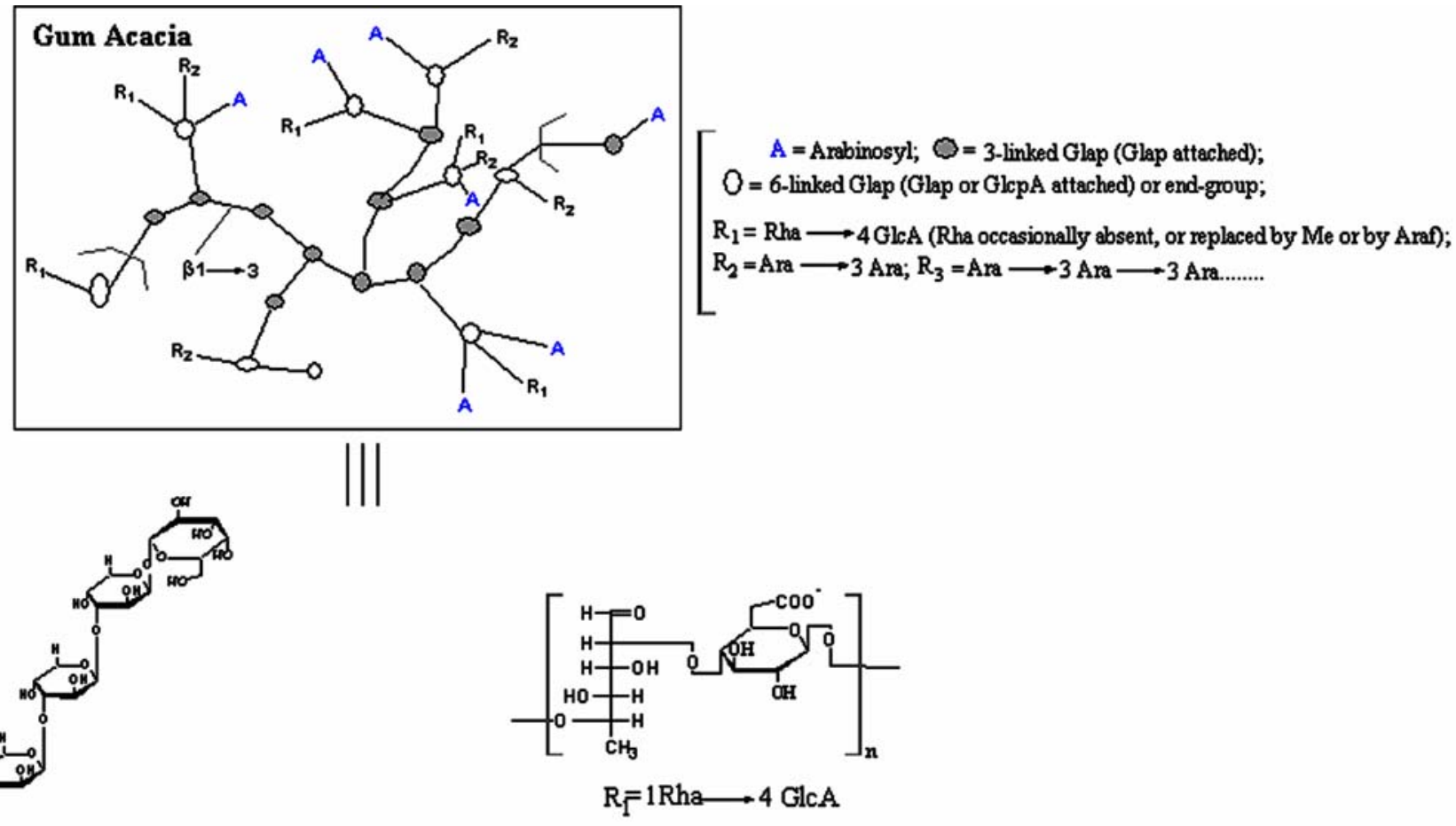

\section{Rhamnose attached with Glucuronic acid}

[II]

\section{$R_{2}=1 \longrightarrow$-linked Glactose backbone attached with Arabinosyl unit}

[I]

Scheme 1 Schematic macromolecular structure of gum acacia, [I] polyanionic side chain and [II] polyol bearing hetero saccharide backbone

present communication devoted on the synthesis of novel electroactive carbohydrate polymer hybrids loaded with PANI and optimize their ratio in order to find out appropriate composition for electrical conduction.

In the accomplished studies, structural, morphological and electrical characterizations were extensively investigated. It would be expected that the results might be helpful in leading to new promising conducting polymers applicable for sensor fabrication. The major advantage of this work is to use carbohydrate polymers and increase their utility in a broader prospective by chemical modifications.

\section{Experimental}

\section{Materials}

Gum acacia (E. Merck) was used after fractional precipitation with ethanol. Aniline (E. Merck) was distilled prior to use and ceric ammonium nitrate (Aldrich) was used without further purification. The deionized water was used for all the reactions.

\section{Synthesis of GA-PANI hybrid}

A calculated amount of the GA was dissolved in minimum required amount of distilled water in a $500 \mathrm{ml}$ flask. To this solution, calculated amount of the aniline and $0.5 \mathrm{M}$ hydrochloric acid were added and the total volume was made up to $200 \mathrm{ml}$. The flask was thermostated at $25 \pm$ $0.2{ }^{\circ} \mathrm{C}$ with continuous stirring. After $30 \mathrm{~min} 0.45 \mathrm{M}$ ceric ammonium nitrate was added and this was taken as zero time. The reaction was allowed for $2 \mathrm{~h}$. The reaction mixture was neutralized by $5 \%$ aqueous $\mathrm{NaOH}$ and hybrid was precipitated with absolute ethanol. The resulting precipitate was repeatedly washed acetone and then with $N$-methyl pyrrolidone (NMP) in order to separate PANI (homopolymer) from the hybrid. Finally, products were dried in a vacuum oven at $50{ }^{\circ} \mathrm{C}$.

\section{Characterization}

An Ocean Optics HR 4000 High Resolution Spectrophotometer was recorded the UV-Vis spectra of the samples. FTIR spectra were recorded on PK-1310, Perkin-Elmer 
instrument by making a pellet with dehydrated $\mathrm{KBr}$ in reflectance mode. Scanning electron microscope (SEM) was done on a JEOL-840, JEOL Corporation, Japan by making a film of desirable size and coated with gold.

\section{Electrical characterization}

The four-point probe method [14] was used for the determination of electrical conductivity of the polyaniline and GA-PANI hybrid by making rectangular pressed pallets (pressure 5 tons $/ \mathrm{cm}^{2}$ ). This method was also followed for the study of $I V$ Characteristics of polyaniline and GA-PANI hybrid both.

According to the four-point probe method the resistivity can be calculated using the relation-

$\rho=2 \pi S(V / I)$

where $S$ is the probe spacing $(\mathrm{mm})$, which was kept constant, $I$ is the supplied current in milliampere, and the corresponding voltage was measured in millivolts.
Conductivity can be computed using the relationship -

$\sigma=1 / \rho$

For the measurements, Keithley four-probe system with 224 programmable current source, 181 nano voltameter and 195A digital multimeter. The electrical conductivity measurements were carried out in the temperature range 0 to $50{ }^{\circ} \mathrm{C}$. The effect of $\mathrm{pH}$ on electrical conductivity of GAPANI was also studied in the range of 1-10.

\section{Results and discussion}

Synthesis and effect of compositions

Gum acacia-polyaniline (GA-PANI) hybrids could be synthesized through oxidative-radical polymerization of polyaniline using ceric ammonium nitrate in acidic medium. Typically, varying the combination of aniline in the molar ratios $0.2-0.4 \mathrm{M}$ with $1 \mathrm{~g} / \mathrm{l} \mathrm{GA}$ was studied with the

\section{[I]}

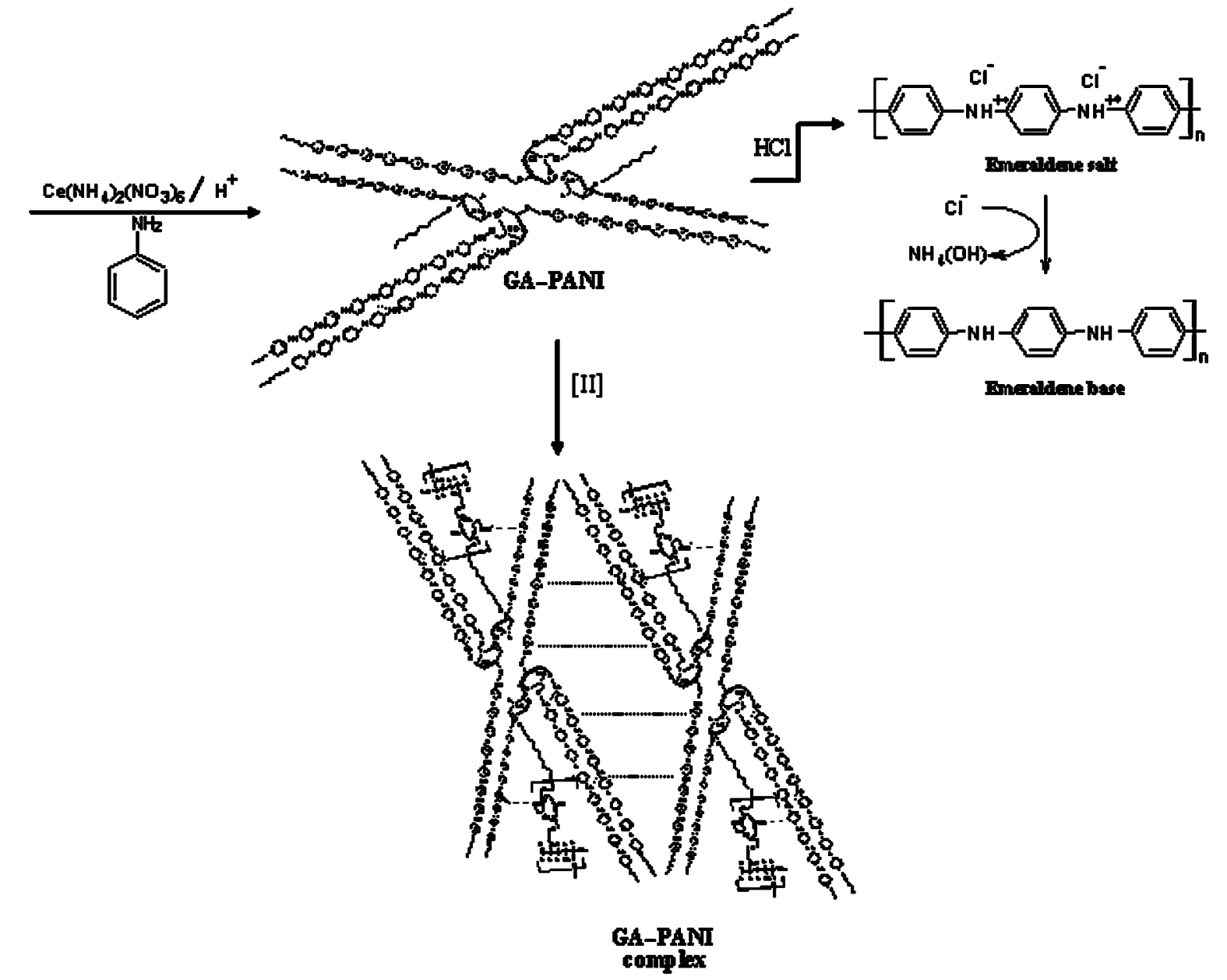

Scheme 2 Synthesis of GA-PANI complex hybrid and its $\mathrm{pH}$ response 
Table 1 Effect of acacia gumaniline ratio, $\mathrm{pH}$ and temperature on electrical conductivity of PANI-AG hybrid

\begin{tabular}{llllll}
\hline Sl. no. & $\begin{array}{l}\text { Aniline-acacia gum } \\
\text { ratio }\end{array}$ & Solubility & $\mathrm{pH}$ & $\begin{array}{l}\text { Temperature } \\
\left({ }^{\circ} \mathrm{C}\right)\end{array}$ & $\begin{array}{l}\text { Electrical conductivity } \\
\left(\mathrm{Scm}^{-1}\right)\end{array}$ \\
\hline 1. & $0.20 \mathrm{M}-1 \mathrm{~g} / 1$ & Water soluble & 7 & 25 & $1.52 \times 10^{-5}$ \\
2. & $0.30 \mathrm{M}-1 \mathrm{~g} / 1$ & Water soluble & 7 & 25 & $6.15 \times 10^{-4}$ \\
3. & $0.40 \mathrm{M}-1 \mathrm{~g} / 1$ & Water soluble & 7 & 25 & $3.88 \times 10^{-4}$ \\
4. & $0.40 \mathrm{M}-1 \mathrm{~g} / 1$ & Water soluble & 1 & 25 & $5.46 \times 10^{-2}$ \\
5. & $0.40 \mathrm{M}-1 \mathrm{~g} / 1$ & Water soluble & 10 & 25 & $2.53 \times 10^{-5}$ \\
6. & $0.40 \mathrm{M}-1 \mathrm{~g} / 1$ & Water soluble & 1 & 0 & $1.27 \times 10^{-2}$ \\
7. & $0.40 \mathrm{M}-1 \mathrm{~g} / 1$ & Water soluble & 1 & 50 & $8.10 \times 10^{-2}$ \\
\hline
\end{tabular}

constant concentration of ceric ammonium nitrate $(0.45 \mathrm{M})$, $\mathrm{HCl}(0.5 \mathrm{M})$ at $25 \pm 0.2{ }^{\circ} \mathrm{C}$. It was observed that hybrid materials were water-soluble and the electrical conductivity increases with increasing the concentration of aniline. It is fact that in the medium of acid, aniline protonated to form $\mathrm{Ph}-\mathrm{NH}_{3}^{+}$and further oxidized to yield polyaniline cation radicals that are quickly grafted onto the available oxygen radicals of [I] GA (i.e. produced at $-\mathrm{OH}$ due to presence of redox initiator). Therefore with increasing concentration of aniline (but not more than $0.4 \mathrm{M}$ ) resulted more loading of polyaniline with in the hybrid. The grafted PANI is showed usual response with $\mathrm{pH}$ and form emeraldene salt i.e. conducting form of PANI at low $\mathrm{pH}$ as well as emeraldene base (insulating form of PANI formed at higher $\mathrm{pH}$ ) as shown in Scheme 2. At lower $\mathrm{pH}$, the grafted PANI have positive charge that ionically attached with GA macromolecules at the polycationic end groups [II] that improve its solubility as well as probably create compact complex structure with electrically active sides for the electrical conduction. All the results are summarized in the Table 1.

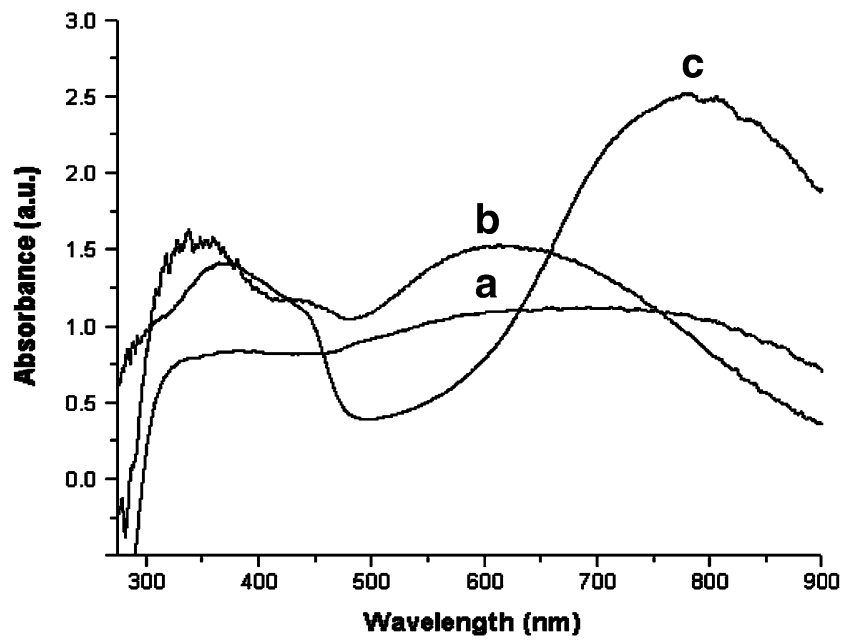

Fig. 1 UV-Vis spectra of $A$ GA-PANI hybrid at $\mathrm{pH} 1 ; B$ GA-PANI hybrid at $\mathrm{pH} 10$ and $C$ PANI at $\mathrm{pH} 1$
UV-vis spectra

The UV-vis spectra of GA-PANI and PANI are shown in Fig. 1. UV-vis spectra of GA-PANI at $\mathrm{pH} 1$ showed a broad absorption band at $300-465 \mathrm{~nm}$ due to overlapping of arabinogalactan components of gum acacia, $\pi-\pi^{*}$ transition of benzenoid rings and polaronic peak of grafted PANI. The peak at $800 \mathrm{~nm}$ was assigned bipolaronic transitions of grafted PANI (Fig. 1a), while GA-PANI at pH 10 showed a peak at $610 \mathrm{~nm}$ due to the $\pi-\pi^{*}$ transition of quinoid rings of the grafted PANI (Fig. 1b). Figure 1c showed typical UV-vis spectra of PANI at $\mathrm{pH} 1$. These curves evidenced that the grafted PANI showed transition 'emeraldine saltemeraldine base' (protonation-deprotonation or dopingdedoping) and bears emeraldine oxidation state in the media of different $\mathrm{pH}$ [15].

\section{FTIR spectra}

Figure 2 showed the FTIR spectra of GA-g-PANI (Fig. 2a) and PANI (Fig. 2b). Figure 2a has characteristic peaks of

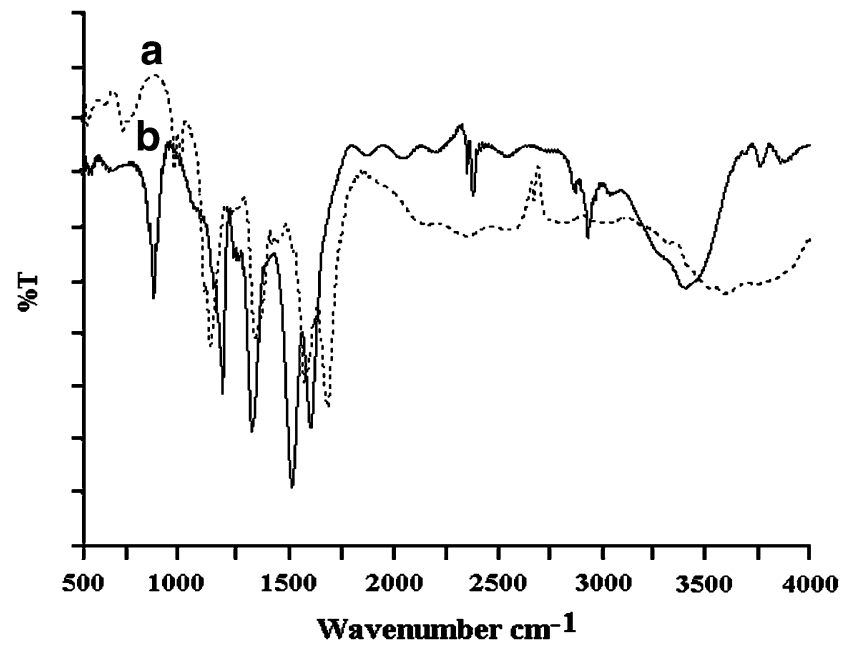

Fig. 2 FTIR spectra of $A$ GA-PANI hybrid and $B$ PANI 
Fig. 3 SEM pictures of a GAPANI hybrid and $\mathbf{b}$ PANI

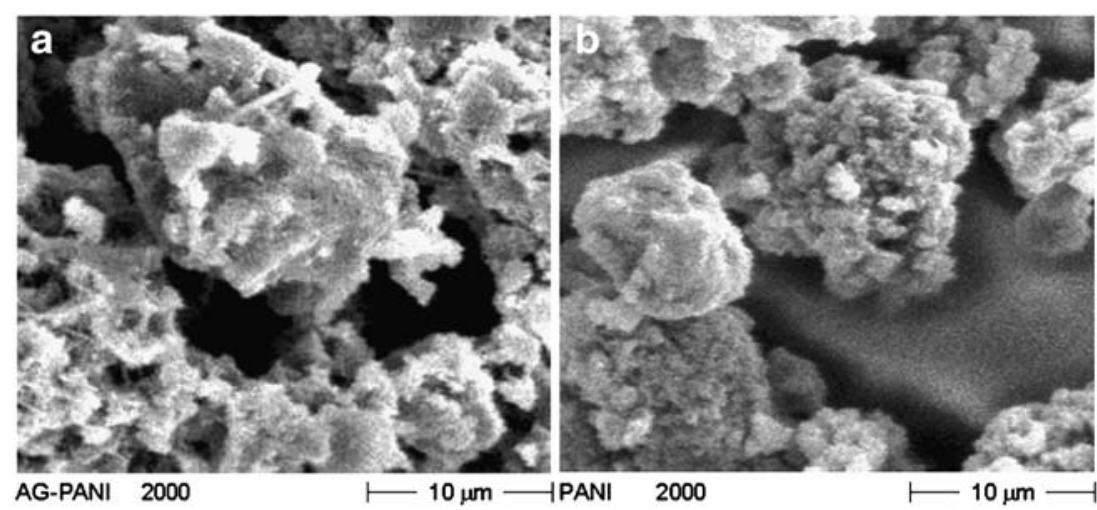

PANI as well as gum acacia. The infrared band at $\nu_{\max }$ 3,040-3,266 $\mathrm{cm}^{-1}$ corresponds to $\mathrm{N}-\mathrm{H}$ stretching with hydrogen bonded $2^{0}$ amino groups and free $\mathrm{O}-\mathrm{H}$ stretching vibration, $\nu_{\max } 3,024 \mathrm{~cm}^{-1}$ corresponds to aromatic $\mathrm{C}-\mathrm{H}$ stretching, $\nu_{\max } 2,930 \mathrm{~cm}^{-1}$ and $\nu_{\max } 2,864 \mathrm{~cm}^{-1}$ (due to aliphatic $\mathrm{C}-\mathrm{H}$ stretching), $\nu_{\max } 1,632 \mathrm{~cm}^{-1}$ (due to $\mathrm{C}=\mathrm{O}$ stretching of carbonyl group, typical sacharide absorption), $\nu_{\max } 1,526 \mathrm{~cm}^{-1}$ (due to $\mathrm{C}=\mathrm{C}$ stretching of quinoid rings), $\nu_{\max } 1,423 \mathrm{~cm}^{-1}$ (due to $\mathrm{C}=\mathrm{O}$ stretching of $-\mathrm{COOH}$ group and $-\mathrm{OH}$ bending of acid group respectively), $\nu_{\max }$ $1,462 \mathrm{~cm}^{-1}$ (due to $\mathrm{C}=\mathrm{C}$ stretching vibration of benzenoid rings), $\nu_{\max }$ at $1,284 \mathrm{~cm}^{-1}$ (due to $\mathrm{C}-\mathrm{N}$ stretching). The absorption band $\nu_{\max }$ at $1,110 \mathrm{~cm}^{-1}$ was assigned to $\mathrm{N}=\mathrm{Q}=\mathrm{N}$ bending vibration shift towards the lower wave number correspond to the PANI. The shift of $\nu_{\max }$ $1,130 \mathrm{~cm}^{-1}$ band to lower wave number could be attributed to the hydrogen bonding between GA and imine group of the grafted chain of PANI. The absorption band at $1030 \mathrm{~cm}^{-1}$ (due to $\mathrm{O}-\mathrm{H}$ bending), at $1,076 \mathrm{~cm}^{-1}$ (characteristic peaks of a saccharide structure; $\mathrm{C}-\mathrm{O}$ stretching) and at $830 \mathrm{~cm}^{-1}$ was assigned to aromatic $\mathrm{C}-\mathrm{H}$ bending vibration band due to the 1,4-disubstituted benzene ring. FTIR spectra of PANI showed the characteristic peaks of the emeraldine salt form of PANI [16].

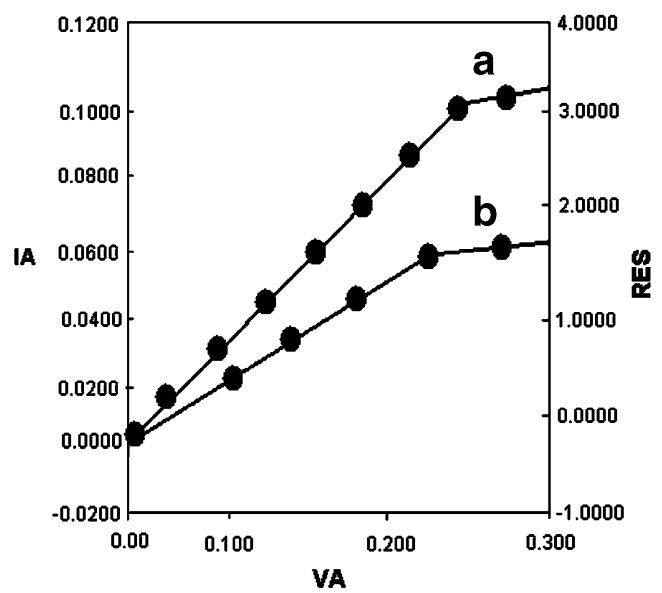

Fig. $4 I-V$ characteristics of $A$ GA-PANI hybrid and $B$ PANI
Scanning electron microscopy

The surface topography of the GA-PANI was studied by scanning electron microscopy (SEM) and compared with the polyaniline. The surface of the GA-PANI seems like suspended globules that were accumulated in contrast to the porous interior structures. This fact can be attributed to the porosity of the suspended globular surface in the hybrid, while polyaniline showed scattered flower like shapes. Hence, the surface evidence supports the homogeneity of the uniform mixing of PANI on to the gum acacia (Fig. 3).

\section{Electrical characterization}

I- $V$ characteristic of the GA-PANI hybrid pellet was evaluated by measuring the voltage with varying current at room temperature. The voltage was measured with varying current at room temperature in order to see whether the GA-PANI hybrid possesses the ohmic contact like polyaniline or rectifying contacts. A linear relationship of the $I-V$ characteristic is shown in Fig. 4. From the results it is observed that the GA-PANI hybrid has an ohmic behavior [17].

The DC electrical conductivity of GA-PANI hybrids, polyaniline and biopolymer GA were measured under laboratory conditions. The results are summarized in the Table 2. The value of DC electrical conductivity was found almost 7,000 times higher than that of parental GA biopolymer. It is due to grafting of PANI on to GA backbone and complexation of polyanionic end groups of

Table 2 Electrical conductivity of PANI, AG and PANI-AG hybrid [(aniline) $0.4 \mathrm{M}$ and $(\mathrm{AG}) 1 \mathrm{~g} / 1]$ at $30^{\circ} \mathrm{C}$

\begin{tabular}{lllll}
\hline S1. No. & Polymer & Solubility & $\mathrm{pH}$ & $\begin{array}{l}\text { Electrical } \\
\text { conductivity } \\
\left(\mathrm{Scm}^{-1}\right)\end{array}$ \\
\hline 1. & PANI & Water insoluble & 1 & 0.742 \\
2. & GA & Water soluble & 1 & $4.73 \times 10^{-6}$ \\
3. & GA-PANI hybrid & Water soluble & 1 & $6.70 \times 10^{-2}$ \\
\hline
\end{tabular}


GA with $\mathrm{HCl}$ doped PANI. The conductivity of the GAPANI hybrid is dependent on temperature. On increasing the temperature, the conductivity increases. It showed that the conduction is purely electronic, where the conductivity is directly proportional to the temperature. The electrical conductivity of PANI-AG hybrid was measured after doping and dedoping with different concentrations of $\mathrm{HCl}$ and $\mathrm{NH}_{3}$ solution respectively at a fixed time (Table 1). The conductivity of the GA-PANI hybrid increases with increasing dopant concentration indicated the formation of emeraldine salt to emeraldine base of the loaded PANI chain in the hybrid. The effect of temperature on the electrical conduction of the hybrid was also measured; all the results have been summarized in the Table 1. It was observed that the electrical conductivity of the material increases with increasing the temperature. It was attributed that the electrical conductivity of the hybrid material was pure electronic not ionic. Hence the electronic features of the hybrid material proved the sensitivity against the acidbase and temperature and showed variation with these variables. Therefore the produced hybrid material could be significantly utilized for the sensing applications.

\section{Conclusions}

A water-soluble, electrically conducting hybrid of Gum Acacia-polyaniline was synthesized using ceric ammonium nitrate as initiator in acidic medium. The optimum electrical conductivity was found at: ceric ammonium nitrate $(0.45 \mathrm{M})$; aniline $(0.4 \mathrm{M})$; hydrochloric acid $(0.5 \mathrm{M})$; GA $(1.0 \mathrm{~g} / \mathrm{l})$, temperature $\left(25 \pm 0.2{ }^{\circ} \mathrm{C}\right)$ and reaction time $(2 \mathrm{~h})$. The resulting hybrids were water-soluble and have $\mathrm{pH}$ switching electrical conduction. Electrical conductivity was found in the range of $1.52 \times 10^{-5} \mathrm{Scm}^{-1}$ to $8.10 \times$ $10^{-2} \mathrm{Scm}^{-1}$. The electrical conductivity was dependent on $\mathrm{pH}$ and the ratio of aniline in the material. $I-V$ characteristic of hybrid showed ohmic behavior during current flow. In conclusion, chemically modified gum acacia have con- trolled electrical conduction by the loading of PANI. Moreover, conducting polymer-carbohydrate polymer hybrids could be usefully exploited as multifunctional electronic materials for technological applications. The materials may be of great importance in the fabricating various sensor devices for in vivo and in vitro applications.

Acknowledgements Author is thankful to the Department of Science and Technology, Govt. of India for generous financial support and to the Director, National Physical Laboratory, New Delhi, India for providing infrastructure facilities to carry out this work.

\section{References}

1. Osman ME, Williams PA, Menzies AR, Phillips GO (1993) J Agric Food Chem 41:71-77

2. Street CA, Anderson DMW (1983) Talanta 30:887-893

3. Sanchez C, Renard D, Robert P, Schmitt C, Lefebvre J (2002) Food Hydrocoll 16:257-267

4. Mallik H, Mukhopadhyay P, Sankar A (2004) Solid State Ionics 175:769-772

5. Mallik H, Sarkar A (2006) J Non-Cryst Solids 352:795-800

6. Yang Y, Yang W (2005) Polym Adv Technol 16:24-31

7. Ghosh P, Chakrabarti A, Siddhanta SK (1999) Eur Polym J 35:803-813

8. Thanpitcha T, Sirivat A, Jamieson AM, Rujiravanit R (2006) Carbohydr Polym 64:560-568

9. Shin SR, Park SJ, Yoon SG, Spinks GM, Kim SI, Kim SJ (2005) Synth Met 154:213-216

10. Yang S, Tirmizi SA, Burns A, Barney AA Jr, Risen WM (1989) Synth Met 32:191-200

11. Kim SJ, Shin SR, Spinks GM, Kim IY, Kim SI (2005) J Appl Polym Sci 96:867-873

12. Xu XH, Ren GL, Cheng J, Lui Q, Li DG, Chen Q (2006) J Mater Sci 41:3147-3149

13. Xu XH, Ren GL, Cheng J, Lui Q, Li DG, Chen Q (2006) J Mater Sci 41:4974-4977

14. Hua MY, Su YN, Chen SA (2000) Polymer 41:813-815

15. Gospodinova N, Terlemezyan L (1998) Prog Polym Sci 23:14431484

16. Lubentsov BZ, Timofeeva ON, Khidekel ML (1991) Synth Met 45:235-238

17. Sengupta PP, Barik S, Adhikari B (2006) Mater Manuf Process $21: 263-270$ 